\title{
Assessment of Low Temperature Damage on Rice Production in 1980 and 1993 in Korea
}

\author{
Yeong-Sang Jung, E Hun Kim, Hong Hyun Kim \\ Department of Biological Environment \\ College of Agriculture and Life Science \\ Kangwon National University, R. O. Korea
}

\begin{abstract}
Assessment of low temperature damage in 1980 and 1993 was attempted with the relationship between the yield index and monthly mean air temperature in Korea. Among the major climatic disasters, the frequency of low temperature damage was lower than the frequencies of drought or flood damage, but the severity in production loss was greater. In 1980, low temperature severely decreased rice yield. The yield index in 1993 was not seriously decreased though the predicted yield index was low due to low temperature.
\end{abstract}

Keywords : low temperature, yield index, rice production

\section{Introduction}

Historical records say that rice was planted three to five thousand years ago in the Korean Peninsula. Since plant growth largely depends upon climatic conditions, production of rice varies as weather changes. Selection of crops and development of appropriate technology based on climatic conditions of the region are core components for stabilizing plant production.

Low temperature often strikes the Korean Peninsula in various type during the last decades. Since biological activities depend upon environmental conditions, a small change in temperature could affect growth and yield of the plants. Rice, the major staple crop, is subject to low temperature damage.

In 1980, low temperature during the summer decreased rice yield and led to shortage of the staple crop. It resulted in a serious decrease in the national economic status. The Rural Development Administration analyzed the low temperature effect on the 1980 rice production, and decided to boost development of proper measures to cope with the damage. Agricultural scientists endeavored to develop cold resistant varieties and cultivation technology. In 1993, another low temperature during the growing season attacked, but rice yield decrease was less serious than in 1980.

This paper reviews effect of climatic variability on rice production and compares low temperature damage on rice yield in 1980 and in 1993 with the climatic data of the Korea Meteorology Administration and the crop situation data collected from the Rural Development Administration to assess low temperature damage on rice in Korea.

\section{Material and Method}

Long term meteorological data were collected from the computer Center of the Korea Meteorology Office. The available mean air temperature and daily precipitation data were from 1908 in Seoul, Daegu and from 1946 in Jeonju and from 1966 in Suwon, and from 1971 in other meteorology observatories. National rice production data were collected from the Ministry of Agriculture and Fishery. Crop situation data were collected from the Research Bureau, Rural Development Administration. Available data of national rice production and crop situation data were from 1946 and from 1964, respectively.

Statistical analyses were conducted with the SAS to eliminate the technological yield increase effect, The crop situation indices were calculated as 


$$
I Y_{x}=\frac{\text { Yield of the year } x}{5 \text {-year average from year } x-2 \text { to } x+2}
$$

\section{Result and discussion}

\section{A. Long term change in climatic conditions and crop production}

Crop production increased rapidly since the 1960's when economic development begun. The variability in rice production was the greatest in the 1940 's, and then decreased. In 1980 , however, a tremendous fall was recorded by low summer temperature.

Since the regular meteorological observation began in 1908, mean air temperature has gradually increased. In Seoul, the change rate is 0.021 to 0.024 from September to June, while is insignificant from July to August. The rate in Kangreung is lower than Seoul ranging from 0.009 to 0.0201 . This implies that warming is ongoing, but is insignificant in July and August possibly due to the rainy season.

Table 1. Seasonal change rate of monthly mean air temperature in Seoul and Kangreung from 1910 to 1990.

\begin{tabular}{|c|c|c|c|c|}
\hline \multirow{2}{*}{ Season } & \multicolumn{2}{|c|}{ Seoul } & \multicolumn{2}{|c|}{ Kangreung } \\
\hline & $\begin{array}{l}\text { Change rate } \\
\left({ }^{\circ} \mathrm{C} / \text { year }\right)\end{array}$ & $\mathrm{R}^{2}$ & $\begin{array}{c}\text { Change rate } \\
\left({ }^{\circ} \mathrm{C} / \text { year }\right)\end{array}$ & $\mathrm{R}^{2}$ \\
\hline March-June & 0.0224 & 0.863 & 0.0201 & 0.846 \\
\hline July-August & 0.0029 & 0.006 & 0.0033 & 0.064 \\
\hline September-November & 0.0209 & 0.289 & 0.0091 & 0.573 \\
\hline November-February & 0.0236 & 0.276 & 0.0172 & 0.613 \\
\hline
\end{tabular}

\section{B. Impact of climatic disaster on Korean agriculture}

Fig. 1 shows the trend of the national average rice yield per unit area and the variability of the yield index. The rice production has been increased markedly since 1960 's, The yield index, however, shows large variability due to climatic disasters.

Three major climatic disaster in rice production in Korea are drought, strong wind and heavy rain, and coolness. Table 2 shows the extent of damaged areas and production losses from 1965 to 1995 when the damaged paddy land exceeded 50,000ha. Among three climatic disasters, flood damage was the most frequent, and the average extent was the greatest. The return period was two years. The return period of drought damage was four years and that of low temperature was seven years. Though the return period of low temperature damage was longer than drought and flood damage, The extent was much larger than the others. In 1980, the damaged area was 63 percents of the total paddy land. The extents of drought damage in 1968 and 1967 were 24 and 18 percents. Since then, the government of Korea invested large inputs to expand irrigation system, and the area damaged by drought was decreased accordingly.

The largest damage to rice production was recorded in 1980 by low temperature. The estimated production loss was as much as 1,583 thousand MT. This corresponded to 35 percents of the normal production, and the loss per damaged area was 2.02MT/ha. Production losses per damaged area in 1971 and 1993 were comparatively smaller than in 1980.

The greatest production loss per damaged area by drought was in 1968 which amounted to $1.83 \mathrm{MT} / \mathrm{ha}$, and the next was $1.71 \mathrm{MT} / \mathrm{ha}$ in 1967. Since then, the government of Korea invested large inputs to expand irrigation, and the area damaged by drought has decreased.

Though damage by heavy rain and wind was frequent, the annual variability of production loss was smaller than low temperature and drought damage. The average yield index of the years damaged by low temperature was 0.86 , while the average yield indices of the years damaged by drought and flood were 0.99 and 0.97 . 
J. Yeong - Sang, E. H. Kim and H. H. Kim
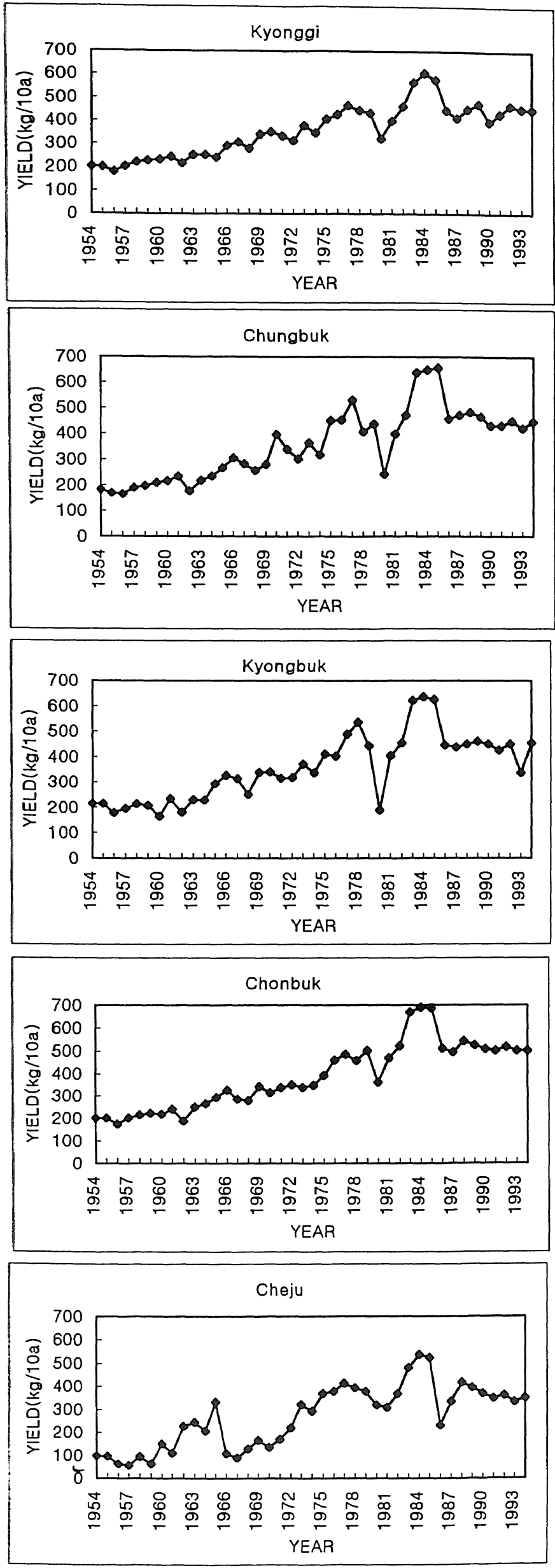
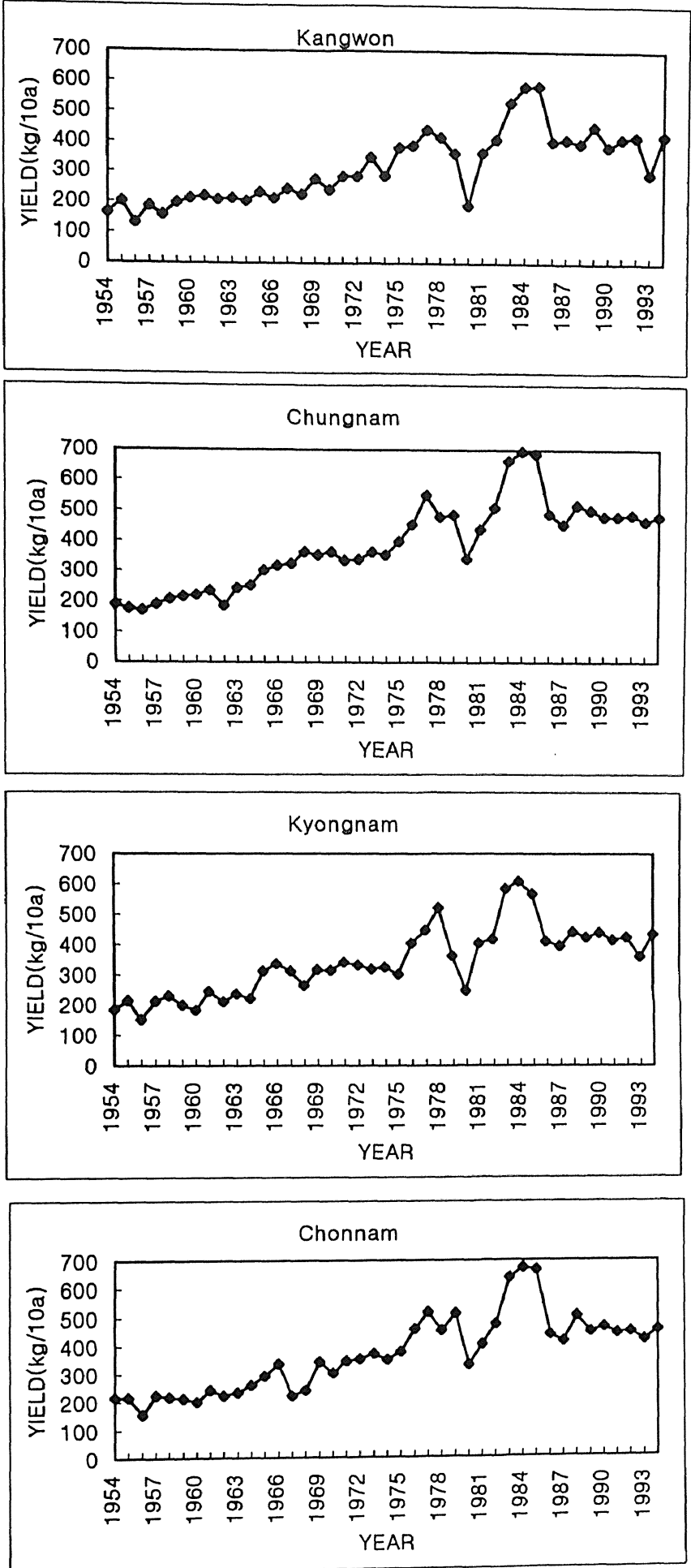

Fig 1. Trend of rice yield in Korea since 1954. 
Table 2. The seriously damaged years by climatic impact on rice cultivation in Korea since 1965 based on impacted area greater than 50,000ha.

\begin{tabular}{|c|c|c|c|c|c|c|c|c|}
\hline \multicolumn{3}{|c|}{ Low temperature } & \multicolumn{3}{|c|}{ Drought } & \multicolumn{3}{|c|}{ Flood } \\
\hline Year & $\begin{array}{c}\text { Area } \\
(1000 \mathrm{ha})\end{array}$ & $\begin{array}{l}\text { Yield } \\
\text { index }\end{array}$ & Year & & $\begin{array}{l}\text { Yield } \\
\text { index }\end{array}$ & Year & $\begin{array}{c}\text { Area } \\
(1000 \text { ha })\end{array}$ & $\begin{array}{l}\text { Yield } \\
\text { index }\end{array}$ \\
\hline $\begin{array}{l}1980 \\
1993 \\
1971\end{array}$ & $\begin{array}{l}782 \\
208 \\
176\end{array}$ & $\begin{array}{l}0.65 \\
0.94 \\
0.98\end{array}$ & $\begin{array}{l}1968 \\
1967 \\
1965 \\
1977 \\
1994 \\
1982\end{array}$ & $\begin{array}{r}310 \\
229 \\
74 \\
64 \\
64 \\
54\end{array}$ & $\begin{array}{l}0.88 \\
0.97 \\
0.95 \\
1.10 \\
1.03 \\
0.99\end{array}$ & $\begin{array}{l}1987 \\
1970 \\
1984 \\
1990 \\
1972 \\
1981 \\
1985 \\
1979 \\
1989 \\
1980 \\
1986 \\
1969 \\
1974\end{array}$ & $\begin{array}{r}399 \\
172 \\
150 \\
122 \\
121 \\
116 \\
111 \\
107 \\
107 \\
104 \\
102 \\
95 \\
95\end{array}$ & $\begin{array}{l}0.95 \\
1.09 \\
1.03 \\
0.98 \\
0.95 \\
0.95 \\
1.01 \\
0.99 \\
1.03 \\
0.65 \\
0.99 \\
1.05 \\
0.99\end{array}$ \\
\hline Mean & 129 & 0.86 & Mean & 132 & 0.99 & Mean & 138 & 0.97 \\
\hline
\end{tabular}

C. Relationship between temperature and yield index of rice.

Table 3 shows the quadratic relationship between the yield index of rice and monthly temperature in Chuncheon. The highest correlation was obtained between the yield index and average temperature of July, August and September. Uchijima(1981). found that the average temperature of July and August was highly correlated to yield index in Japan.

The mean monthly temperature from July to September for the maximum yield index, MTEMP, was $23.67^{\circ} \mathrm{C}$. Since the normal mean monthly temperature from July to September was $22.7^{\circ} \mathrm{C}$, the yield index in the normal year was calculated as 1.04 . Warmer temperature by $1^{\circ} \mathrm{C}$ than the present normal year would show the maximum yield index in Chuncheon.

Table 3. Quadratic relationship between the yield index of rice, IY and monthly mean temperature, $\mathrm{T}_{\mathrm{m}}$.

\begin{tabular}{|c|c|c|c|c|}
\hline $\begin{array}{l}\text { Independent } \\
\text { variable }\end{array}$ & IY & $\begin{array}{l}\text { Model } \\
C-\operatorname{coeff}\left(T_{x}-M T E M P\right)^{2}\end{array}$ & + MIY & $\mathrm{R}^{2}$ \\
\hline $\begin{array}{l}\text { July temp. } \\
\text { August temp. } \\
\text { September temp. } \\
\text { July-August temp. } \\
\text { Aug. -Sept. temp. } \\
\text { July-Sept. temp. }\end{array}$ & $\begin{array}{ll}\mathrm{T}_{7} & \text { IY } \\
\mathrm{T}_{8} & \text { IY } \\
\mathrm{T}_{9} & \text { IY } \\
\mathrm{T}_{78} & \text { IY } \\
\mathrm{T}_{89} & \text { IY } \\
\mathrm{T}_{789} & \text { IY }\end{array}$ & $\begin{array}{l}=-0.0159\left(T_{7}-27.53\right)^{2} \\
=-0.0207\left(T_{8}-25.70\right)^{2} \\
=-0.0300\left(T_{9}-20.28\right)^{2} \\
=-0.0238\left(T_{78}-27.19\right)^{2} \\
=-0.0352\left(T_{89}-22.90\right)^{2} \\
=-0.0670\left(T_{789}-23.67\right)^{2}\end{array}$ & $\begin{array}{l}+1.161 \\
+1.050 \\
+1.069 \\
+1.193 \\
+1.066 \\
+1.105\end{array}$ & $\begin{array}{l}0.484^{* x} \\
0.326^{x x} \\
0.276^{* x} \\
0.653^{x z} \\
0.425^{x z} \\
0.763^{x z}\end{array}$ \\
\hline
\end{tabular}

*The models showed significancy at $\mathrm{p}=0.01$ with the model with ${ }^{* *}$ and at $\mathrm{p}=0.05$ with

Table 4. shows the C-coefficient, MIY, MTEMP and $\mathrm{R}^{2}$ of the quadratic model with the independent variable of the mean monthly temperature from July to September. The correlation coefficients, $\mathrm{R}^{2}$, of Kangwon and Kyungbuk regions were higher than the other regions. These two regions were subject to low temperature damage, and faced to the east coast. 
Table 4. Quadratic relationship between the yield index of rice and monthly mean temperature from July to September.

\begin{tabular}{lcccc}
\hline \hline Region & C coeff & MIY & MTEMP & $\mathrm{R}^{2}$ \\
\hline Kangwon & -0.0670 & 1.105 & 23.67 & 0.742 \\
Kyeonggi & -0.0410 & 1.030 & 24.69 & 0.512 \\
Chungbuk & -0.0363 & 1.067 & 24.74 & 0.455 \\
Chungnam & -0.0323 & 1.041 & 24.55 & 0.501 \\
Jeonbuk & -0.0363 & 1.121 & 25.21 & 0.420 \\
Jeonnam & -0.0410 & 1.030 & 24.69 & 0.512 \\
Kyungbuk & -0.0457 & 1.089 & 25.40 & 0.758 \\
Kyungnam & -0.0433 & 1.060 & 24.69 & 0.558 \\
\hline
\end{tabular}

D. Assessment of the low temperature damage on rice production in 1980 and 1993

The statistical model developed was applied to 1980 and 1993 crop data. The estimated yield indices were from 0.2 to 0.4 in the high mountainous area, 0.4 to 0.8 in the east coastal area, and 0.7 to 0.9 in the plain area. These were close to agricultural statistics, while the crop situation experiment showed higher yield indices due to adopting higher resistant varieties. The predicted yield index was fairly close to actual yield index in 1980, but is underestimated in 1993. This might be due to adopting cold resistant varieties. In warming climatic conditions, the overall net primary productivity might increase, however, the crop situation index of rice would decrease for 2 or $3^{\circ} \mathrm{C}$ warming with the present model. Varietal development to cope with this situation is necessary.

Table 5. Assessment of low temperature damage in rice production in 1980 and 1993

\begin{tabular}{|c|c|c|c|c|c|}
\hline \multirow{2}{*}{ Region } & \multicolumn{2}{|c|}{1980} & \multicolumn{2}{|c|}{1993} & \multirow{2}{*}{$\begin{array}{c}\text { Normal } \\
\text { year } \\
\text { PIY }\end{array}$} \\
\hline & PIY & AIY & PIY & AIY & \\
\hline Kangwon & 0.539 & 0.49 & 0.706 & 0.75 & 1.008 \\
\hline High $\mathrm{MT}^{1}$ & 0.473 & 0.20 & 0.253 & 0.15 & 1.058 \\
\hline Mid $\mathrm{MT}_{3}^{2}$ & 0.817 & 0.79 & 0.689 & 1.09 & 1.020 \\
\hline Plain & 0.856 & 0.79 & 0.787 & 1.09 & 0.969 \\
\hline East Coast & 0.285 & 0.42 & 0.629 & 0.82 & 1.005 \\
\hline Kyeonggi & 0.649 & 0.78 & 0.789 & 1.02 & 0.926 \\
\hline Chungbuk & 0.716 & 0.75 & 0.879 & 0.96 & 1.022 \\
\hline Chungnam & 0.687 & 0.69 & 0.853 & 0.97 & 0.993 \\
\hline Jeonbuk & 0.791 & 0.72 & 0.886 & 0.99 & 1.095 \\
\hline Jeonnam & 0.741 & 0.75 & 0.899 & 0.94 & 0.987 \\
\hline Kyungbuk & 0.498 & 0.40 & 0.651 & 0.80 & 1.037 \\
\hline Kyungnam & 0.699 & 0.56 & 0.826 & 0.87 & 1.037 \\
\hline
\end{tabular}

* High $\mathrm{MT}^{1}$, Jinbu ; Mid MT ${ }^{2}$, Cheolwon; Plain ${ }^{3}$, Chuncheon; East Coast ${ }^{4}$, Kangrung, respectively

\section{Conclusion}

The analysis on climatological data together with crop situation data collected from the Meterological Administration and the Rural Development Administration of Korea was conducted to assess low temperature damage on rice crop production. 
Crop situation indices from 1976 to 1990 , normalized by the yield trend model, were correlated with temperature deviations from normal. The July, August and September temperature anomalies were highly correlated with the crop situation indices. The statistical model developed was applied to $1993 \mathrm{crop}$ data. The estimated yield indices were from 0.2 to 0.4 in the high mountainous area, 0.4 to 0.8 in the east coastal area, and 0.7 to 0.9 in the plain area. These were close to agricultural statistics, while crop situation experiment showed higher yield indices due to adopting higher resistant varieties.

\section{Acknowledgement}

This paper was prepared with the financial support from the Korea-Japan Science Cooperation Committee, the Korea Research Foundation, Ministry of Education, Korea. Authors express deep appreciation to Dr. Yosei Hayashi in the National Institute of Agro-Environmental Sciences, Japan for his suggestions on the project.

\section{References}

Uchijima, Z. 1981. Yield variability of crops in Japan. Geojournal, 5(2):151-164

Yoshino, M., T. Horie, H. Seino, H. Tsujii, T. Uchijima, Z. Uchizima. 1987. The effect of climatic variations on agriculture in Japan. In the Impact of Climatic Variations on Agriculture, Part VI., Vol. I(Eds., M. L. Parry, T. R. Carter, N. T. Konijn):723-876

Jung, Y. S., N. Tani. 1984. Characterisitics and distribution of agroclimatic resources in Korea. The Symposium in Memory of the 10-Year Korea-Japan Cooperative Research in Agriculture. RDA-JICA:77-98 